\title{
DEVELOPMENT OF A HIGH-PRESSURE HYDROGEN INJECTION FOR SI ENGINE AND RESULTS OF ENGINE BEHAVIOR
}

\author{
K. S. VARDe and G. A. Frame \\ Department of Mechanical Engineering, University of Michigan-Dearborn, Dearborn, MI 48128, U.S.A.
}

(Received 4 April 1985)

\begin{abstract}
A high-pressure hydrogen injector was designed and developed in the laboratory. The injector was hydraulically operated by a separate pump. Measurement of injection characteristics on a bench stand showed very repetitive performance of the injector. The injection system was used to supply hydrogen fuel to a singlecylinder spark ignition engine. Results of the tests showed that the engine performance was superior to that achieved with carbureted gasoline fuel.
\end{abstract}

\section{NOMENCLATURE}

BMEP brake mean effective pressure, $\mathrm{kPa}$

MBT min. spark advance in crank degrees for best torque $\triangle \mathrm{P} \quad$ maximum difference in peak cylinder pressure, $\mathrm{kPa}$ $\overline{\mathrm{P}}$

\section{INTRODUCTION}

The concept of hydrogen as a fuel for combustion engines is not new. Hydrogen has been explored as an engine fuel for a long time because of its ability to burn efficiently at lean mixtures and to investigate knocking associated with its combustion (King et al., 1948, 1958; Ricardo, 1923). Recent interest in hydrogen has been to use it as a fuel for gasoline engines (Homan et al., 1978; Swain and Adt, 1972; Varde and Lucas, 1974; etc.) and as a supplementary fuel to extend operating range of spark ignition engines in the lean mixture region (Houseman and Hoehn, 1974; McDonald, 1976; Parks, 1976).

A problem generally experienced in carbureted hydrogen engines is the backfiring. Since minimum ignition energy for hydrogen-air mixture, shown in Table 1, at stoichiometric condition is over an order of magnitude lower than that for gasoline mixture, localized hot points in the chamber and the temperature of residual gas are sometimes sufficient to cause backfiring. One of the methods of overcoming this is to supply hydrogen directly into the cylinder during the compression stroke. Such an approach can have three distinct advantages:

(1) Backfiring can be avoided since hydrogen comes in contact with air in the cylinder and not in the intake manifold. In addition, induction of only air during suction process can reduce existence of hot spots when hydrogen is injected during the compression stroke.

(2) A carbureted hydrogen engine generally develops lower maximum power compared to an equivalent gasoline engine due to restricted air flow. This can be avoided by injecting hydrogen in the cylinder.

(3) Although hydrogen fueled engines can be operated at very lean equivalence ratios, problems associ- ated with such operation can limit the practical range of mixture strength that can be used in engines. A recent study by Drexl et al. (1977) claims that a too lean hydrogen mixture increases ignition delay and causes severe cyclic variations. By injecting hydrogen, the quantity of fuel supplied during each cycle can be metered more precisely than in a carbureted hydrogen engine. This can help in reducing the relative magnitude of cyclic variations.

Direct hydrogen injection has been used by Furuhama and Azuma (1978) and by Homan et al. (1978) with encouraging results. In the present work, an injector for gaseous fuels was developed and tested with hydrogen fuel. The injector was hydraulically operated by a pump driven by the engine. This paper discusses the development and the preliminary engine performance results obtained with this injection system.

\section{HYDROGEN INJECTION SYSTEM}

The hydrogen fuel injection system comprised of two main components: a pump and an injector. The pump was used to pressurize a hydraulic fluid to high pressure and deliver the pressurized fluid to the injector mounted on the cylinder head. The pump comprised of a plunger reciprocating in a barrel, similar to the arrangement used in diesel engine pumps. The plunger was driven by its camshaft which was geared to the engine. The amount of hydraulic fluid delivered to the injector was controlled by a rack on the pump; this allowed smooth and precise control over the delivery of the hydraulic fluid.

Table 1. Comparison of properties of hydrogen and gasoline

\begin{tabular}{lll}
\hline & Hydrogen & Gasoline \\
\hline Lean equivalence ratio & 0.1 & 0.6 \\
Max. flame speed $(\mathrm{m} / \mathrm{s})$ & 2.91 & 0.38 \\
Quenching distance, mm (stoich) & 0.64 & 2.84 \\
Flame temp. at stoich K (1 atm) & 2380 & 2300 \\
Flame temp. at stoich K (100 atm) & 2490 & 2405 \\
Min. ignition energy (J) & 0.00002 & 0.00055 \\
Energy content $\left(\mathrm{MJ} \mathrm{kg}^{-1}\right)$ & 24.5 & $9.2(\mathrm{gas})$ \\
\hline
\end{tabular}




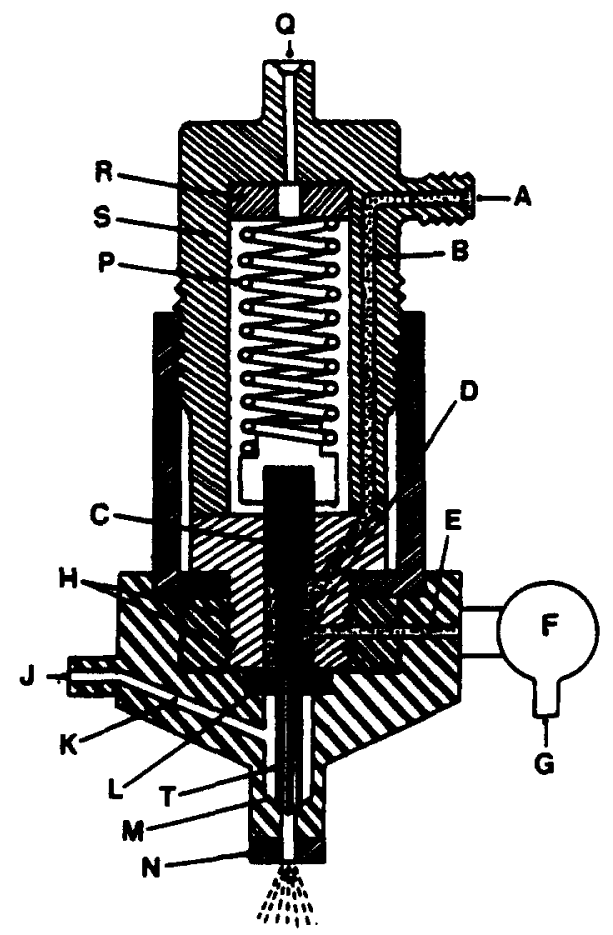

A. FLUID IN FROM PUMP

B. FLUID PASSAGE

C. NEEDLE

D. FLUID RETURN PASSAGE

E. Mating passage

F. RELIEF VALVE

G, FLUID TO TANK

H. SEALS

J. HYDROGEN GAS IN

K. HYDROGEN PASSAGE

L. COMBINED SEAL

$M$. NEEDLE SEAT

N. INJECTION NOZZLE

P. SPRING

Q. FLUID LEAK-OFF

R. COMPRESSION SPACER

S. INJECTOR BODY

T. HYDROGEN INJECTION NEEDLE

Fig. 1. Injector design and details.

The pressurized fluid was supplied to the injector by a high pressure steel tubing. Figure 1 shows the details of the injector. Hydraulic fluid enters the injector at $A$ and communicates with the injector needle valve $C$ via the fluid passage, as shown. The needle valve is kept from lifting up by preload on spring $P$ due to spacer $R$. The spring preload was set such that the needle valve lifted up its seat $M$ when the fluid pressure was about $10 \mathrm{MPa}$. The hydraulic fluid is prevented from leaving the injector through passage $D$ by a relief valve $F$. The relief valve communicates with $D$ via another passage $E$ and a circular groove. The relief valve is adjustable and its opening pressure can be set to any desired value greater than the needle lift pressure. Once the relief valve opens, the hydraulic fluid leaves the injector at $G$ and is dumped back into a tank that supplies fluid to the engine driven pump. Pressure build-up in the hydraulic fluid in the injector between the opening of the needle valve $C$ and the relief valve $F$ guarantees positive lift of the needle valve without jitter. The high pressure fluid is prevented from leaking out of the injector mating surfaces by two circular compressed seals $H$, as shown in Fig. 1. The lower seal $H$ and a combination of metal and rubber seal $L$ prevents the fluid from seeping out into the hydrogen passages. $A$ leak-off outlet, $Q$, is provided at the top of the injector for any hydraulic fluid that may leak from the clearance between the needle valve and the walls of the cylinder.

Compressed hydrogen gas at constant inlet pressure enters the injector at $J$ and is connected to a small hydrogen reservoir $T$ by a passage $\mathrm{K}$. Hydrogen gas cannot flow out through the injector orifice until the needle valve is lifted from its seat by the hydraulic fluid. The injector nozzle $\mathbf{N}$ is removable so that the geometrical configuration of the injector orifice can be changed. The quantity of hydrogen gas injected in the engine could be varied either by changing the injection period or by altering the inlet gas pressure or both.

\section{TEST RESULTS OF INJECTOR OPERATION}

The injector, together with its pump, was mounted on a test bench to evaluate injector operation and hydrogen flow rates that could be achieved with its operation. The pump was driven at a constant speed of $15 \mathrm{rev} \mathrm{s}^{-1}$ corresponding to the engine speed of $30 \mathrm{rev}$ $\mathrm{s}^{-1}$. Gaseous fuel at a constant pressure of $1.03 \mathrm{MPa}$ was supplied to the injector. Fuel flow rates were measured by a calibrated flow meter between the hydrogen pressure regulator and the inlet point on the injector. A pressure transducer was used to measure the duration of needle lift and hence injection period. Figure 2 shows the duration of needle lift when the flow rate of gas was $0.02 \mathrm{~g} \mathrm{~s}^{-1}$ at $15 \mathrm{rev} \mathrm{s}^{-1}$ pump speed. The injection duration for this case was about 37 engine crank degrees. Figure 3 shows a similar pattern when the gas flow rate was increased to $0.125 \mathrm{~g} \mathrm{~s}^{-1}$ at the same pump speed. For this operating condition the injection duration was about 116 degrees of engine crankshaft. Analysis of a number of consecutive needle lift traces showed that the injector operation was very repetitive. 


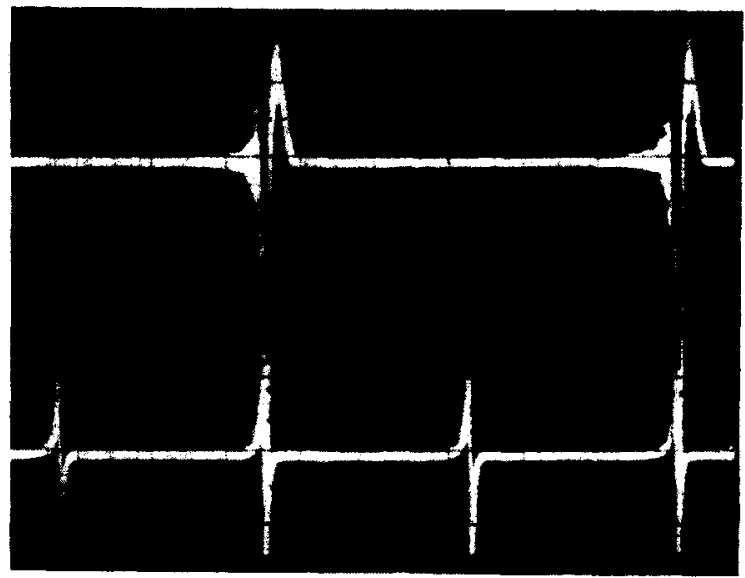

HYDROGEN FLOW: $0.02 \mathrm{GM} / \mathrm{S}$

INJ. DURATION: 37 CRANK DEG.

PUMP SPEED: $15 \mathrm{REV} / \mathrm{S}$

Fig. 2. Needle lift traces at low flow rates.

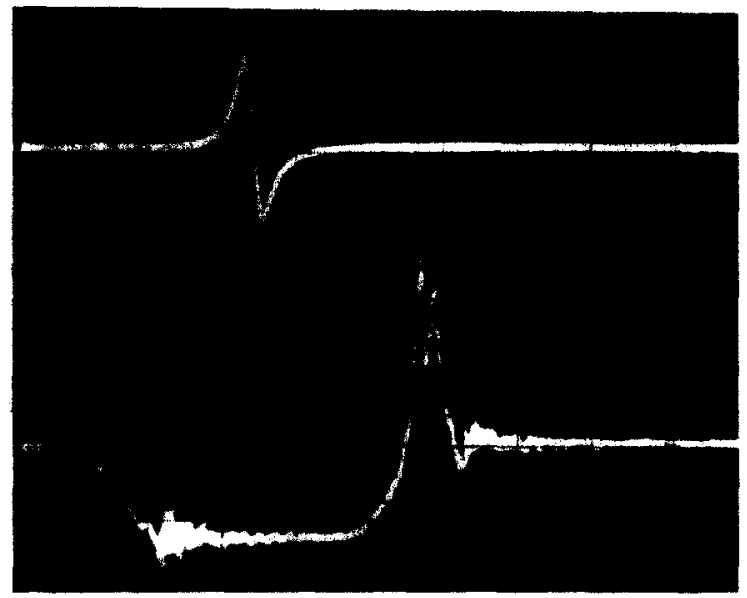

HYDROGEN FLOW: $0.125 \mathrm{GM} / \mathrm{S}$

INJ. DURATION: 116 CRANK DEG.

PUMP SPEED: $15 \mathrm{REV} / \mathrm{S}$

Fig. 3. Needle lift traces at high flow rates.

\section{TEST ENGINE AND PROCEDURE}

The injector was mounted on a single cylinder, four stroke, air cooled, spark ignition engine, shown in Fig. 4. The engine had a bore of $76.2 \mathrm{~mm}$, a stroke of $82.5 \mathrm{~mm}$ and a compression ratio of 5.9 . The cylinder head of the engine was modified to accommodate the injector, spark plug and ionization probes to detect flame travel time. The engine was coupled to a waterbrake dynamometer for loading purposes.

An air-cooled Kistler pressure transducer in a sparkplug adaptor was installed on the cylinder head to measure cylinder pressure. The transducer amplifier output was fed to a Tektronix oscilloscope as well as to a sampler where random cycles could be selected to determine cyclic pressure fluctuations in peak cylinder pressure during combustion.
The hydraulic pump of the injection system was run at half the engine speed by a set of gears on the engine crankshaft and the pump camshaft. The start of hydrogen injection could be altered by changing the relative positions of the pump and the crankshaft gears. In all the tests, hydrogen pressure supplied to the injector was kept fixed at $900 \mathrm{kPa}$ and the flow rate was changed by varying the injection duration.

The engine was started on gasoline and the throttle was adjusted to get the desired load at the desired engine speed. Although it was possible to start the engine directly on hydrogen, starting on gasoline was preferred to conserve hydrogen fuel during warm-up and initial test setting. The engine was then switched over to run on pure injected hydrogen without altering the throttle or the speed. Hydrogen flow rates were changed to evaluate lean operation of the engine. All 


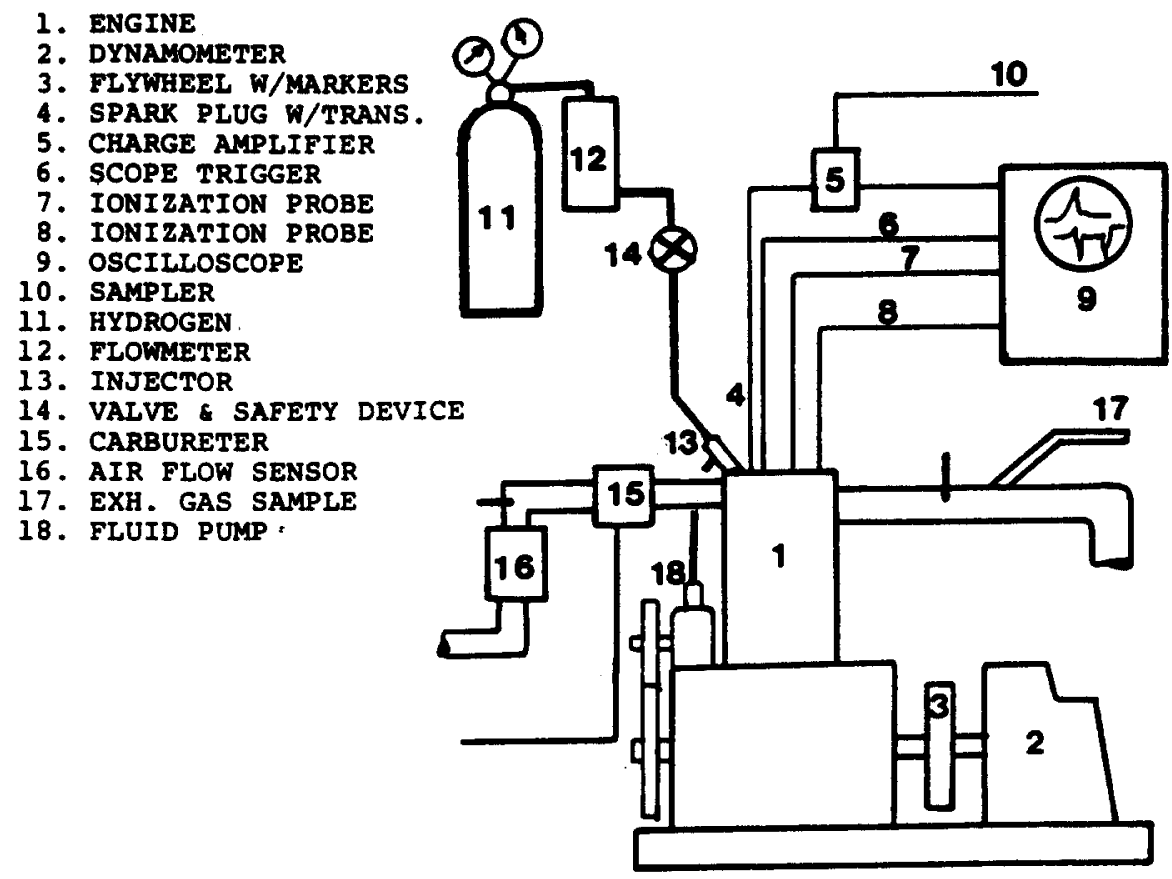

Fig. 4. Engine instrumentation.

the tests discussed in this paper were conducted when the beginning of hydrogen injection was 130 crank degrees before top dead center (BTDC), when the inlet valve was completely closed. Thus, no hydrogen was allowed to enter the intake manifold. The injector was equipped with a single orifice nozzle, $3 \mathrm{~mm}$ in diameter.

Air flow rate to the engine was measured by a thin film flow meter. Samples of dry exhaust gas were withdrawn and analyzed for pollutant species. Oxides of nitrogen $\left(\mathrm{NO}_{x}\right)$ were measured by a chemiluminescent $\mathrm{NO}-\mathrm{NO}_{x}$ analyzer while unburned hydrocarbons $(\mathrm{HC})$ were measured by a FID hydrocarbon analyzer.

\section{ENGINE RESULTS AND DISCUSSION}

Hydrogen flow rates were varied to change the equivalence ratio of the hydrogen-air mixture at a constant engine speed of $25 \mathrm{rev} \mathrm{s}^{-1}$. Tests were conducted by changing the injection duration period, as described earlier. Figure 5 shows the effect of mixture strength on brake thermal efficiency of the engine when fueled by direct hydrogen injection and by carbureted gasoline fuel. Lean operation of the engine on gasoline fuel was very limited at this speed while the range of operation is very much extended when hydrogen injection was used. The lowest equivalence ratio of the hydrogen-air mixture for steady engine operation was about 0.42 with this injection arrangement. This ratio is lower than the corresponding value in our earlier work using electronic hydrogen injection (Varde and Frame, 1982). However,
Homan de Boer and McLean (1978) were able to run a single-cylinder spark ignition engine with direct hydrogen injection at a much lower ratio than achieved in the present case.

Efforts to run the engine at low equivalence ratio resulted in large pressure fluctuation in the cylinder

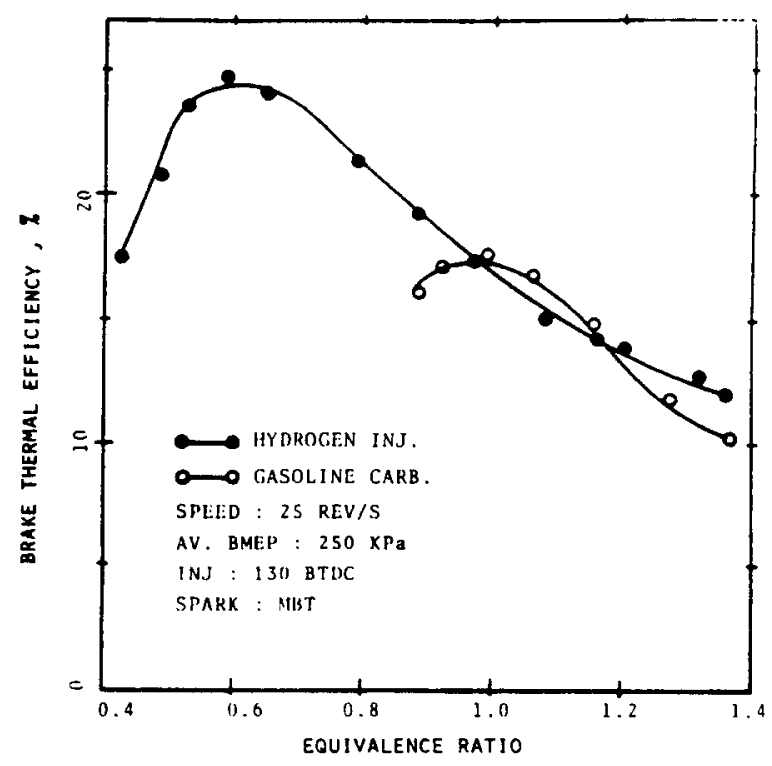

Fig. 5. Thermal efficiency variation with equivalence ratio. 


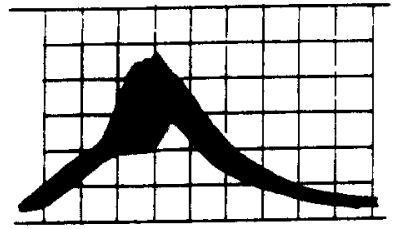

BNGINE SPEED: 25 REV/S EQUTVALENCE RATIO: 0.35 SPEED: 25 REV/S SPARX TIMING: MBT VERTICAL: $340 \mathrm{KPa} / \mathrm{DIV}$ HORI ZANTAL: 2 MS/DIV

Fig. 6. Traces showing cyclic pressure variations.

during combustion process, as shown in Fig. 6. This gave rise to unsteady engine operation and occasional misfiring. The relatively high limiting value of the equivalence ratio in the present case is believed to be due to improper mixing of the injected hydrogen and air in the cylinder. The arrangement of the cylinder head was such that the injector nozzle orifice was close to the exhaust valve and away from the main volume of the combustion chamber. This, along with the geometry of the combustion chamber, could limit proper mixing of the injected hydrogen with air. Efforts are now underway to change the location of the injector and the injector nozzle.

The effect of variation in equivalence ratio on cyclic fluctuations in peak cylinder pressure is shown in Fig. 7. About 100 randomly selected cycles were used to determine cyclic pressure fluctuation parameter, $\Delta P / \bar{P}$. Not much difference in the parameter occurs for equivalence ratios greater than about 0.85 . At these ratios, hydrogen mixture has much higher characteristic flame speed than equivalent gasoline mixture; hence, the relative effect of turbulence on pressure variations would not be as pronounced as for a gasoline fueled engine. In addition, variation in the amount of fuel injected per cycle can be expected to be low based on the bench test analysis of a number of needle lift traces. As the mixture is made leaner, improper mixture formation can lead to increase in cyclic pressure variations.

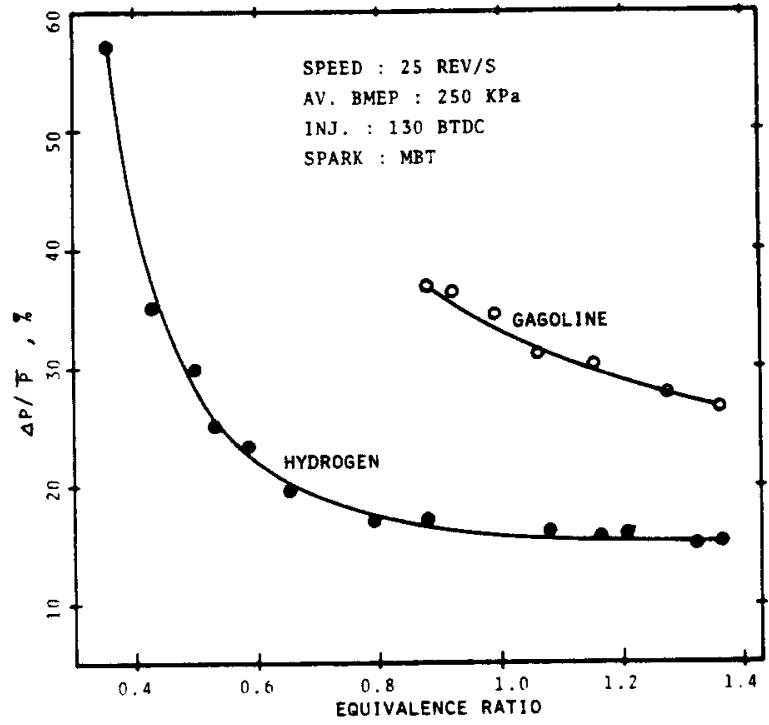

Fig. 7. Cyclic pressure variations for hydrogen injection.

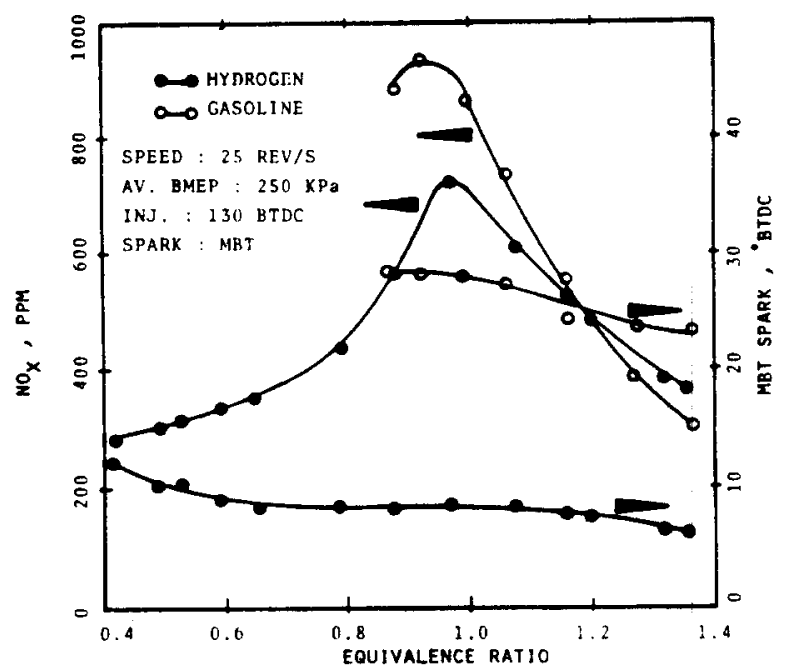

Fig. 8. MBT spark timing and NOx emission.

The levels of oxides of nitrogen measured in the exhaust gases are shown in Fig. 8. It is known that $\mathrm{NO}_{x}$ emission depends on combustion temperature, availability of oxygen and time available for its kinetic process. Although hydrogen-air mixture has slightly higher adiabatic fiame temperature, the MBT spark timing for a hydrogen fueled engine has considerably less advance than for the gasoline engine, as shown in Fig. 8. Thus, the time available for the $\mathrm{NO}_{x}$ mechanism was less resulting in lower peak $\mathrm{NO}_{x}$ levels for hydrogen fuel. In fact, variation in MBT spark timing for hydrogen

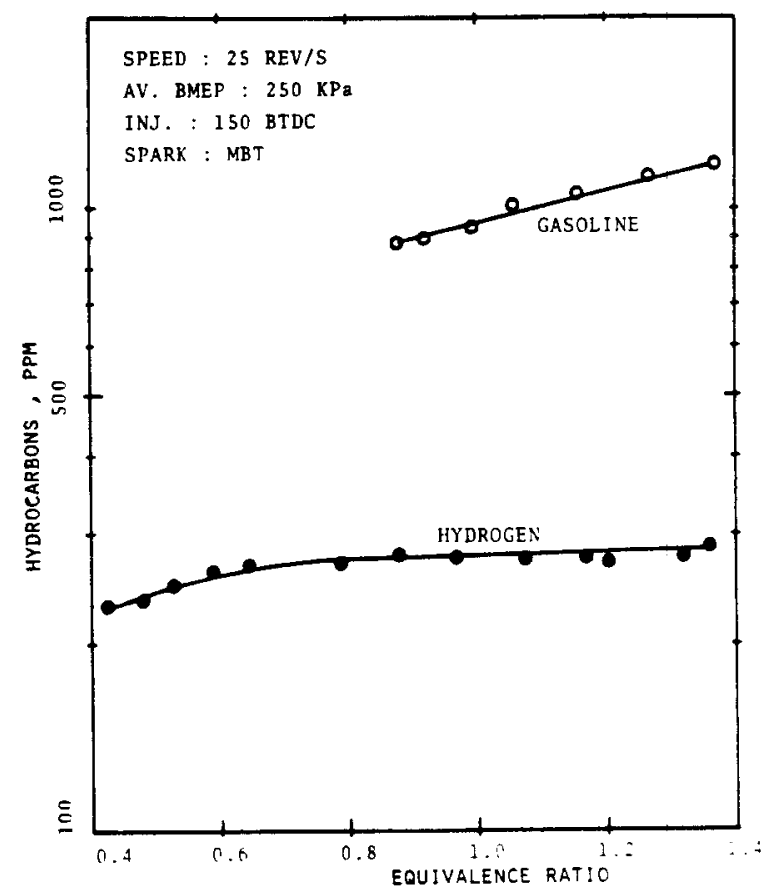

Fig. 9. Hydrocarbon emission with equivalence ratio. 
mixtures at equivalence ratios greater than 0.5 was very small. $\mathrm{NO}_{x}$ levels peak around stoichiometric due to higher combustion temperature and availability of sufficient oxygen.

Emission of unburned hydrocarbons from the engine is shown in Fig. 9. Theoretically, a hydrogen-fueled engine should not emit unburned hydrocarbons except for those emitted from the lubricating oil. The level of $\mathrm{HC}$ emitted by the engine when fueled by direct hydrogen injection were considered to be high and it was thought that some hydraulic fluid may be leaking out in the cylinder. To check this, experiments were conducted by removing the injector and supplying hydrogen in the intake manifold. The results showed $\mathrm{HC}$ emission levels were comparable to those shown in Fig. 9 when direct hydrogen injection was used.

\section{SUMMARY}

Test results showed satisfactory performance of the injector. Injector needle lift showed good repeatability. Engine tests showed the brake thermal efficiency was higher than the corresponding values with carbureted gasoline fuel in lean operating range. Variations in cyclic peak cylinder pressure were lower compared to gasoline fuel operation. Lean operating range of the engine was limited to hydrogen-air equivalence ratio of about 0.42 probably due to hydrogen-air mixing problems. MBT spark timing for hydrogen fuel was less advanced resulting in lower emission of oxides of nitrogen.

\section{REFERENCES}

K. W. Drexl, H. Holtz and M. Gutmann. Characteristics of a single cylinder hydrogen fueled S.I. engine using various mixture formation methods. Report of Daimler-Benz AG., Central Research, Germany (1977).

S. Furuhama and H. Azuma, Hydrogen injection two stroke spark ignition engine. Proc. 2nd World Hydrogen Energy Conference, Vol. IV (1978).

H. S. Homan, P. C. T. de Boer and W. J. McLean, The effects of fuel injection on NOx emissions and undesirable combustion for hydrogen fueled piston engines. SAE Paper 780945 (1978). $J$ J Houseman, F. W. Hoehn, A two-charge engine concept: hydrogen enrichment. SAE Paper 741169 (1974).

R. O. King, Hydrogen engine and the nuclear theory of ignition. Can. J. of Research, Vol. 26, Sec. F (1948).

$R$. O. King, The hydrogen engine-combustion knock and related flame velocity. Trans E.I.C., Vol. 2, 4 (1958).

J. S. McDonald, Evaluation of the hydrogen supplemented fuel concept with an experimental multi-cylinder engine. SAE Paper 760101 (1976).

F. B. Parks, A single cylinder study of hydrogen-rich fuels. SAE Paper 760099 (1976).

M. R. Ricardo, Further notes on fuel research. Proc. Auto Eng'g. (London), Vol. 18 (1923).

M. R. Swain and R. R. Adt, The hydrogen-air fueled automobile. Proc. 7th IECEC, Vol. 1 (1972).

K. S. Varde and G. A. Frame, A study of combustion and engine performance using electronic hydrogen fuel injection. Proc. 4th World Hydrogen Energy Conference, Vol. 2 (1982). K. S. Varde and G. G. Lucas, Hydrogen as a fuel for vehicle propulsion. Proc. Inst. Mech. Engr., Vol. 188 (1974). 